Paper 26

\title{
A Remnant Brown Bear Population in Southern Norway and Problems of its Conservation
}

\author{
KÅRE ELGMORK \\ Zoological Institute, University of Oslo, Postbox 1050, Blindern, Oslo 3, Norway
}

\section{INTRODUCTION}

About the year 1850 the brown bear Ursus arctos arctos L. was common in forested areas over most of Norway, with a population estimated at several thousand individuals (Helland 1913). The development of better fir earms, in certain places combined with changes in the environment, radically changed this situation within a hundred years. By 1969, it was estimated that only 25-50 brown bears were left (Myrberget 1969). The majority of these individuals are connected with larger populations in neighbouring countries (Fig. 1).

Only one small isolated population still exists, situated less than $100 \mathrm{~km}$ to the north-west of Oslo in the so-called Vassfaret Area, named from one of the main forested valleys.* The population has been under study during the past 25 years. The aim of this study has been to follow the destiny of this small population, isolated in a restricted area exposed to increasing human invasion and influence. Some major results on distribution and population development in the period 1949-73 will be presented here. Previous results are given in Elgmork $(1954,1962,1966 \mathrm{a}, 1966 \mathrm{~b}, 1969)$. A more comprehensive account will be published elsewhere (Elgmork in press), as well as results on other topics such as seasonal occurrence, food and feeding behaviour etc. (Elgmork in prep.).

In the period 1969-73, the Vassfaret Valley was studied by a team of biologists under the International Biological Programme, Section CT (Conservation of Terrestrial Communities). The results of the bear studies undertaken in this project will be published elsewhere and are not included in the present material. When these investigations are referred to in the text, the symbol (IBP-CT in prep.) is used.

\section{STUDY AREA}

The general situation of the study area is illustrated in Fig. 1. The bear area given on the map in Fig. 2 is defined as the Main Area, covering about $1400 \mathrm{~km}^{2}$ of which $1200 \mathrm{~km}^{2}$ are forested. The Main Area has been divided into 5 zones.

Bears are also occasionally reported from adjacent districts and reports from an area covered by a circle within a radius of $90 \mathrm{~km}$ are included in the material. This is referred to as the Surrounding Area, covering approximately $25000 \mathrm{~km}^{2}$.

* Since this paper was sent to the Editor, evidence has been accumulating which indicates the existence of another isolated, small population in Hordaland county, about $60 \mathrm{~km}$ east of Bergen. 


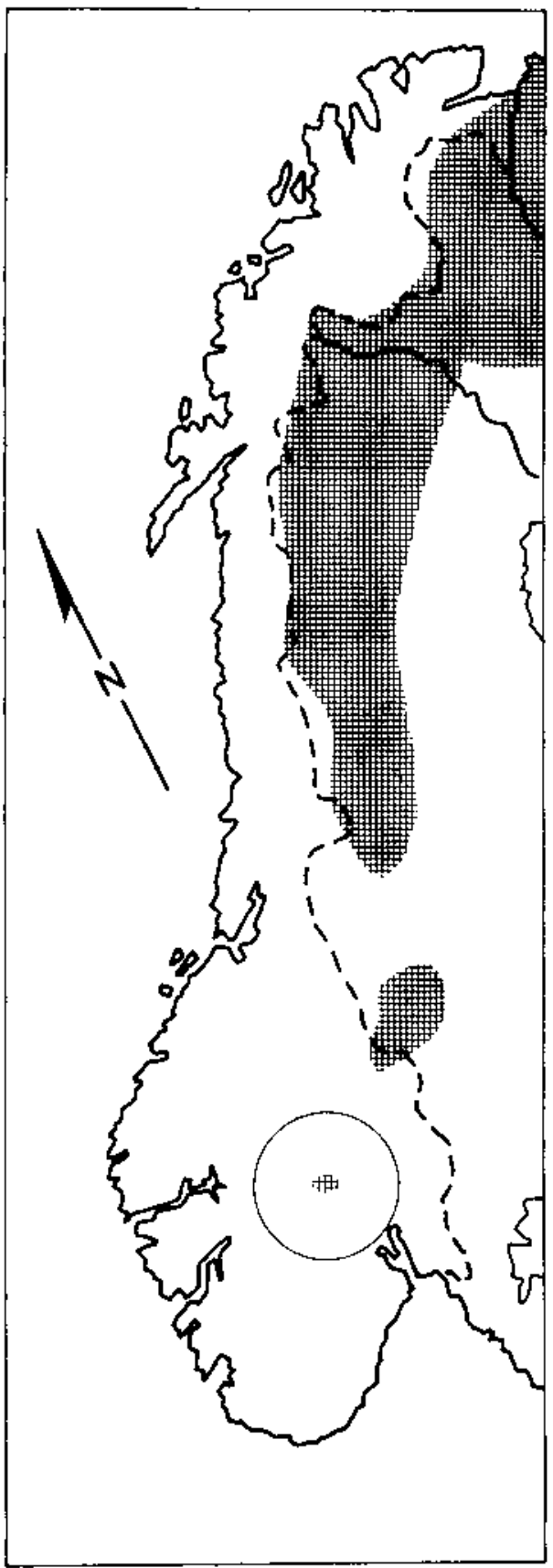

Fig. 1. Approximate distribution of the brown bear in Scandinavia about 1970. Occasional observations have also been made outside the hatched areas.

The circle gives a general idea of the limits of the Surrounding Area. 


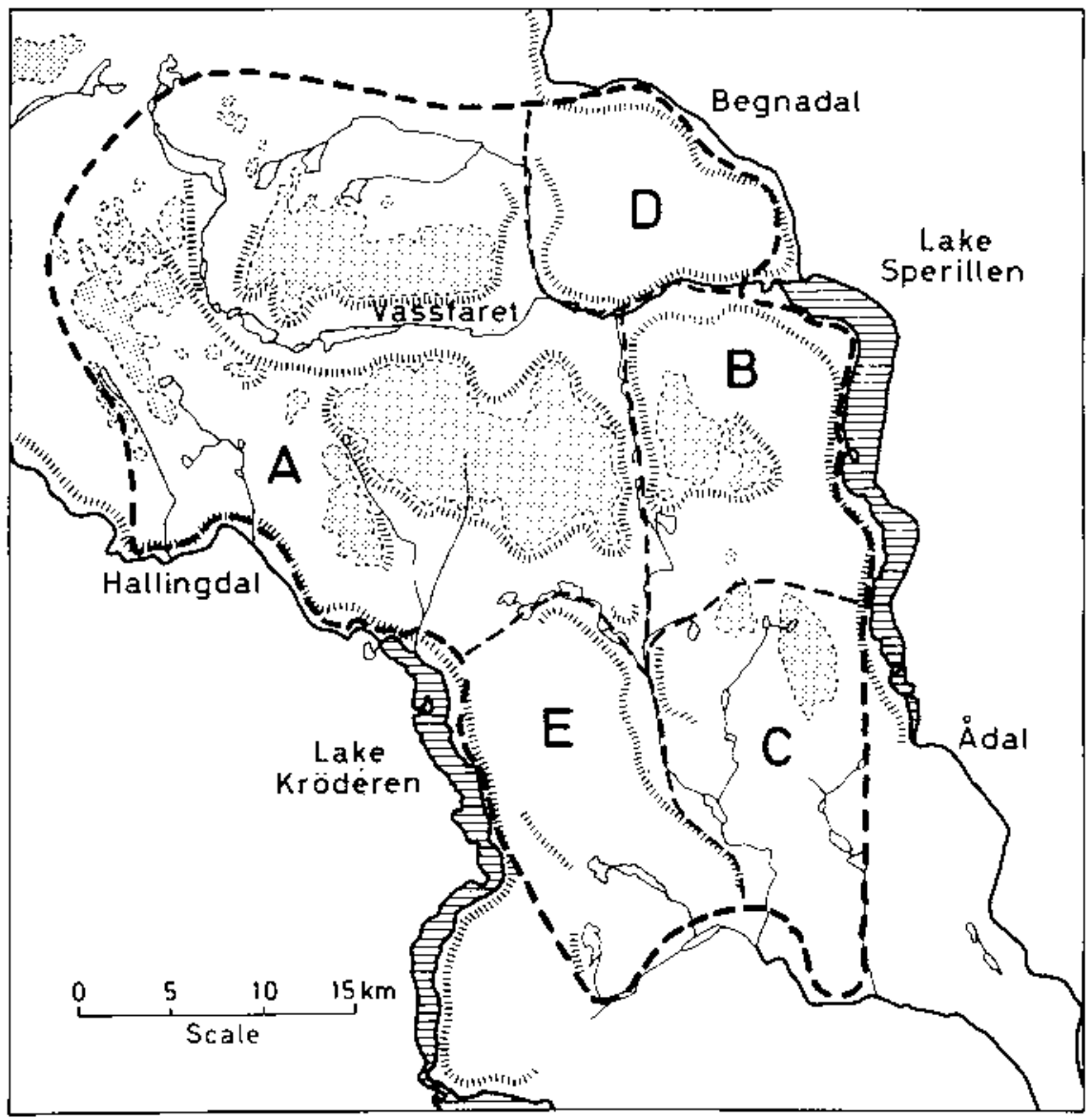

Fig. 2. Study Area: the five Zones $A$ to $E$ of the Main Area are indicated and the more heavily marked outer boundary is that of the Surrounding Area. The finer dashes, enclosing the stippled areas, mark the $900 \mathrm{~m}$ contour, which also approximates to the timberline (cf. Fig. 4).

The Main Area is composed of forests intermingled with alpine plateaus with the timberline situated about $900-1000 \mathrm{~m}$ above sea level (Fig. 3). The dominating and climax forming forest tree is the spruce picea abies (L.).

Along the forested valleys, especially in Zone A, steep and rugged subalpine slopes with snowslides are found near the timberline. Parts of these areas have a lush vegetation suitable for the bears, especially in the spring. These areas are difficult for man to traverse, and the bears have found here a niche relatively uncisturbed by man. Most of the known dens are situated in this type of habitat (IBP-CT in prep.). The presence of this type of landscape is probably important in explaning why this became the last resort of an isolated brown bear population (Elgmork 1966a \& b). 


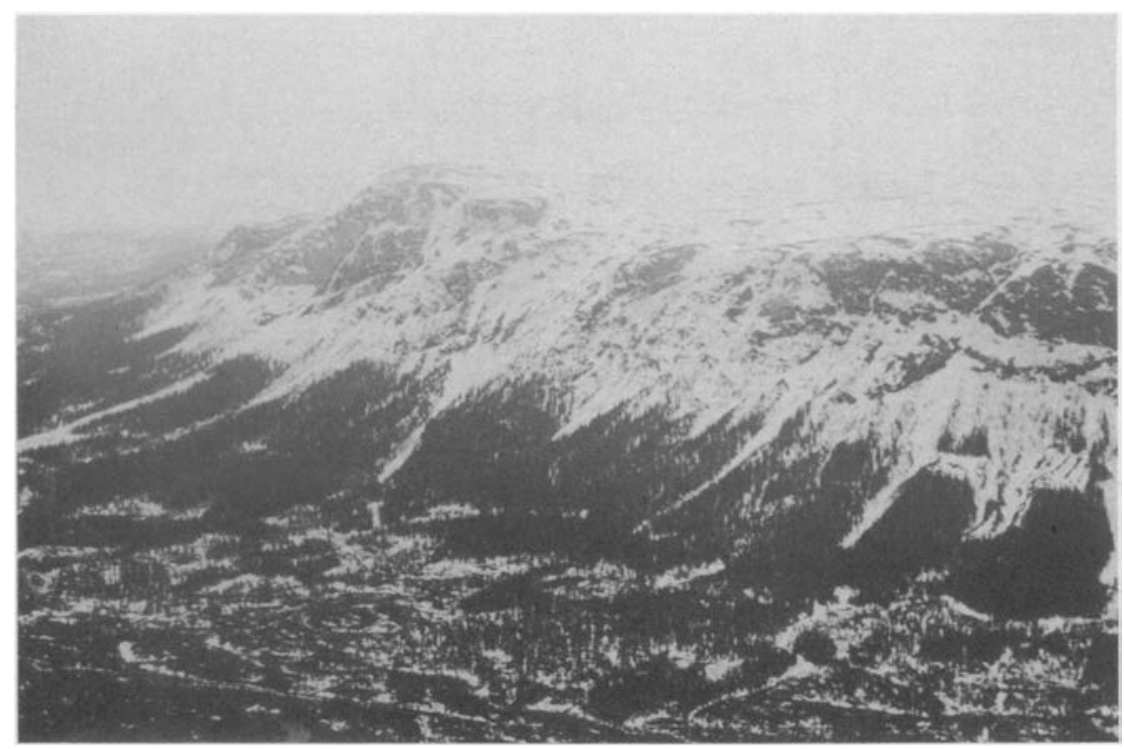

Fig. 3. Main ecological zonation in the core area of the bear habitat. Aerial photograph from the eastern part of the Vassfaret Valley looking south-east, 15 May 1970. From the bottom:

1. Lower forests traversed by forestry roads and clearcuttings. Elevation 500-600 $\mathrm{m}$ above sea level.

2. Highly elevated forests, not yet heavily utilized.

3 . Steep forest-alpine slopes near the timberline at $900-$ $1000 \mathrm{~m}$ above sea level. Denning areas.

4. Alpine plateau with elevation up to $1200 \mathrm{~m}$ above sea level. This zone is not frequented by the bears.

(Photo. K. Elgmork)

The Main Area and its immediate surroundings are sparsely inhabited by man, with a mean density of about 2-3 permanent residents per $\mathrm{km}^{2}$. Human habitation is concentrated in the valleys and in some small forest communities as shown in Figs. 4 and 5 (right: pp. 287, 299).

At the beginning of the study period the Main Area was one of the least disturbed wilderness areas in southern Norway, which also helps to explain the preservation of a remnant brown bear population in this area.

The picture has changed radically during the study period and most of the forested area has gradually been invaded by mechanized for estry, including the building of a large number of forestry roads and the use of large clearcuttings. After the forests were opened up by the roads, an extensive building of private holiday cabins followed, as well as other forms of tourism (Figs. 4 \& 5 , right).

An attempt has been made to quantify some of the human factors in Fig. 6 B and C. Fig. 6 B gives a survey of the development of forestry based on statistical material from the Main Area and adjacent districts. Altogether, the diagrams indicate a rather extensive utilization of the forests, with a steady in- 
crease in the lengths of forestry roads and in clear-cut areas. The length of forestry roads and summer tractor roads increased by 13 per cent over all or from about 50 to $400 \mathrm{~m}$ per $\mathrm{km}^{2}$ of forest in Zone A, and from about $250 \mathrm{~m}$ to nearly $900 \mathrm{~m}$ in Zone C. Cutting class I (clear-cutting) and II (early successional stage) as the mean for the two counties constituting the bear area, increased from 7 per cent around 1950 to about 24 per cent in 1963 . In the southern part of the Main Area the percentage in 1950 was considerably higher than the mean. Other areas, especially in Zone A, lag behind the mean values.

Tourism can be divided into hiking tourism and the building of private holiday cabins. Fig. $6 \mathrm{C}$ gives an estimated curve for the increase in the number of houses, predominantly private cabins, in the Main Area. The density of cabins is highest in Zone B with about 2 per $\mathrm{km}^{2}$ of forest. The relatively few houses present at the beginning of the study period were mostly associated with summer pastures and dairy farms, the majority of which were no longer in use at that time.

\section{MATERIAL AND METHODS}

In spite of a large number of sampling trips to the bear area, only a very few random bear observations were made. Consequently, the study had to rely mainly on second and third hand observations which were gathered from many sources. These are personal communications, interviews, both direct and through questionnaires, and newspaper clippings. A total of 430 reports are now available. The collecting of interviews is being continued.

A problem with information of the above type is the authenticity of the reports. About 3 per cent of the material was discarded as false, while about 27 per cent of the material was characterized as doubtful and treated separately. About 6 per cent was confirmed by the author or some other biologist. The material was re-evaluated at the end of the study period to ensure equal treatment.

Of special concern were the newspaper clippings (43 per cent). These proved, however, to be more reliable than expected. Of 247 newspaper clippings available 60 have so far been checked by field studies, personal communications or interviews. In all cases the basic information in the newspaper clippings corresponded with the personal reports. There were only some exaggerations and minor inconsistencies in details.

The authenticity of the material is supported in different ways. Most reports came from local newspapers and from the local population. The majority of accepted reports are claimed to be visual observations, while the large majority of doubtful reports are of tracks and signs.

Assuming a similar proportion of error throughout the study period and for different population categories, the relative parameters should be uninfluenced by the error.

Final support for the reliability of the material is the arrangement and logical pattern of the emerging results, as e.g. systematic trends and statistically significant similarities and differences in the material. Such results cannot be explained on the basis of material dominated by false reports. Nor are the results in agreement with known variations of other mammals that might be suspected to lead to false bear reports.

The material is consequently interpreted on the basic assumption that variations in the number of reports reflect parallel variations in the population. 


\section{$1949-53$}

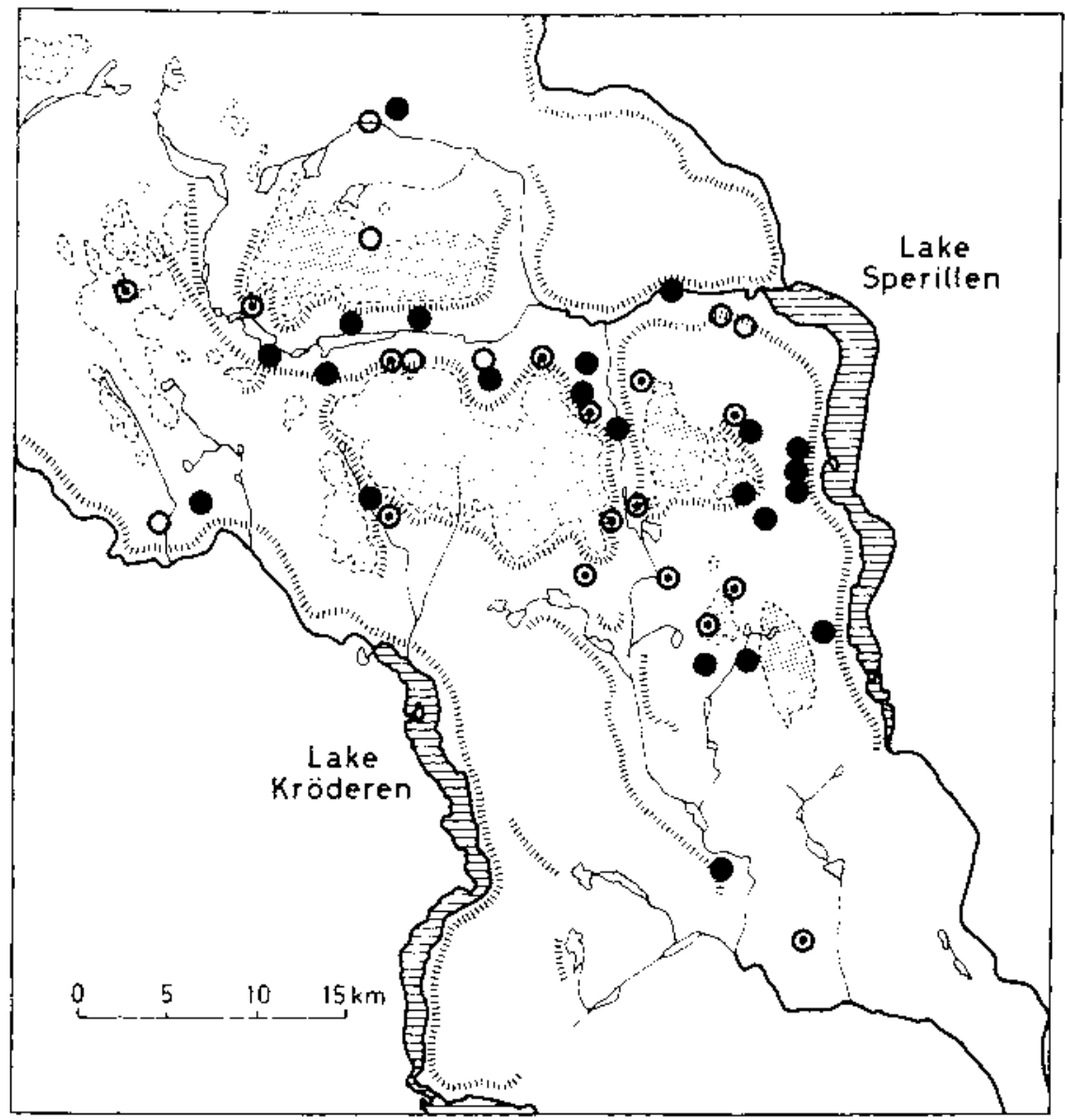

Fig. 4 (left). Accepted bear observations. Two or more independent reports of the same occurrence and reports of different observations made within the same month and less than $5 \mathrm{~km}$ apart are condensed into one symbol as follows:

- Newspaper reports.

- Personal reports and interviews.

- Doubtful, observation not fully acceptable.

ab Above the timberline. 


\section{9}

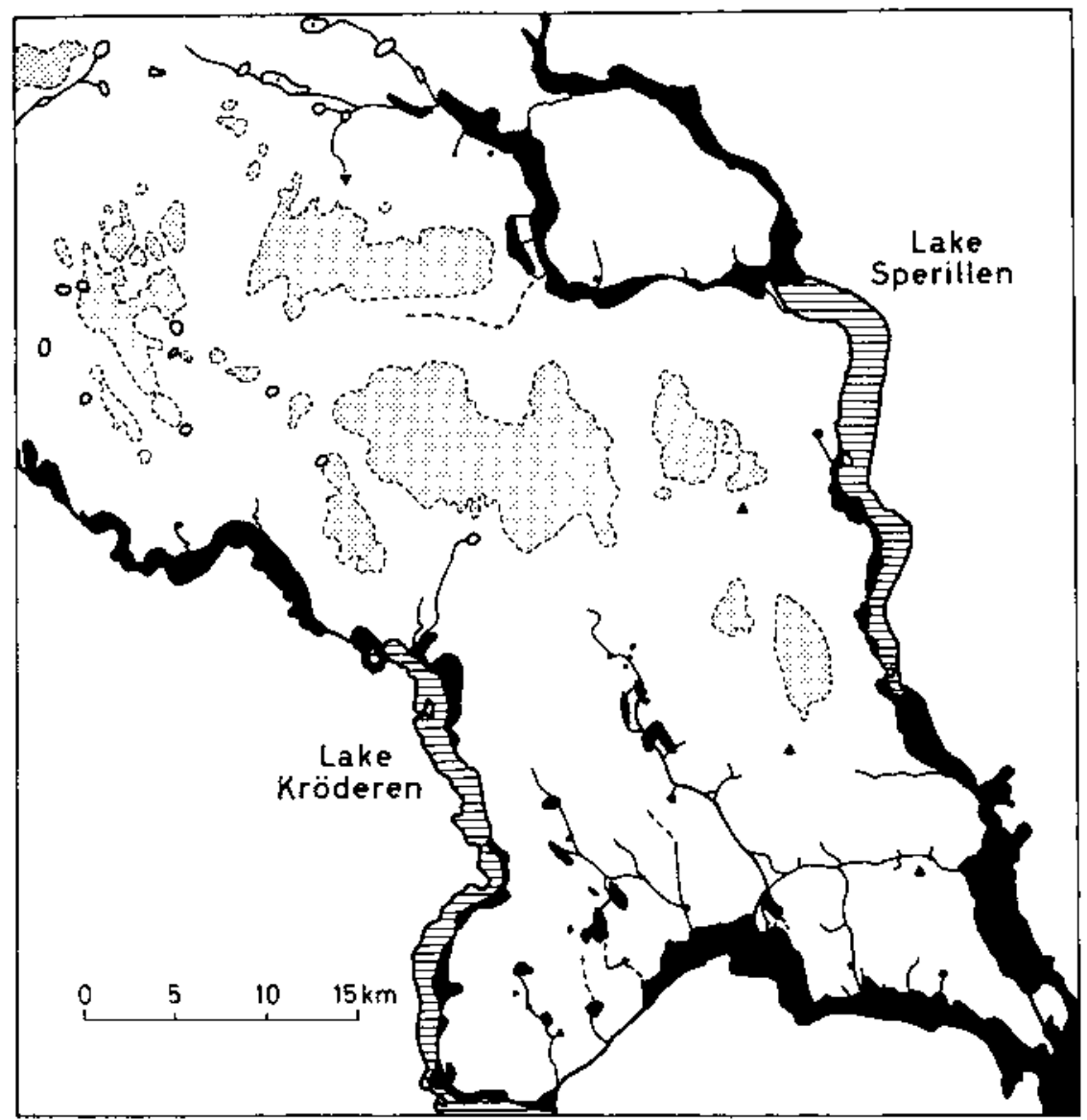

Fig. 4 (right). Indicators of human activities.

Black areas: permanent habitation with agriculture, variably interspaced with forest.

Circumscribed areas with or without dots: not permanently inhabited but with 5 or more cabins or houses less than $500 \mathrm{~m}$ apart. Each dot represents 10 cabins or houses. Absence of dots indicates 5-9 cabins or houses.

Triangles: lodging open to the public

Apex up: Norwegian Tourist Association cabins

Apex down: Mountain hostel

Thicker lines: public roads open throughout the year

Thinner lines: forestry roads, varying in quality but passable for cars, though many are closed in winter and some are open to special permit holders only.

Broken lines: tractor roads not usable by cars.

Stippled areas: above the timberline. 
$1969-73$

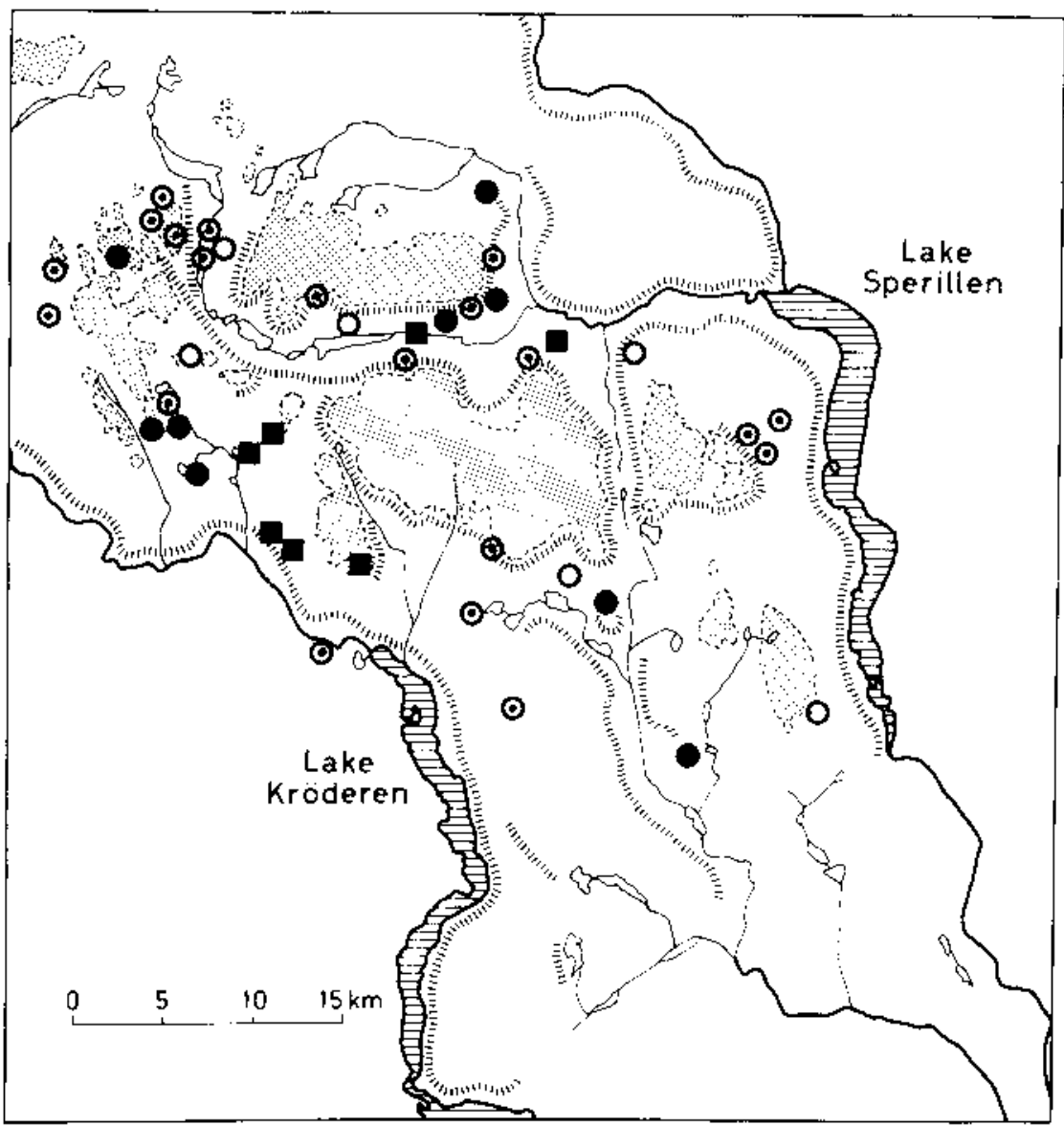

Fig. 5 (left). Accepted bear observations. Two or more independent reports of the same occurrence and reports of different observations made within the same month and less than $5 \mathrm{~km}$ apart are condensed into one symbol.

- Reports controlled by the author and found to be authentic.

- Newspaper reports.

- Personal reports and interviews.

O Doubtful, observation not fully acceptable.

Above the timberline. 
1973

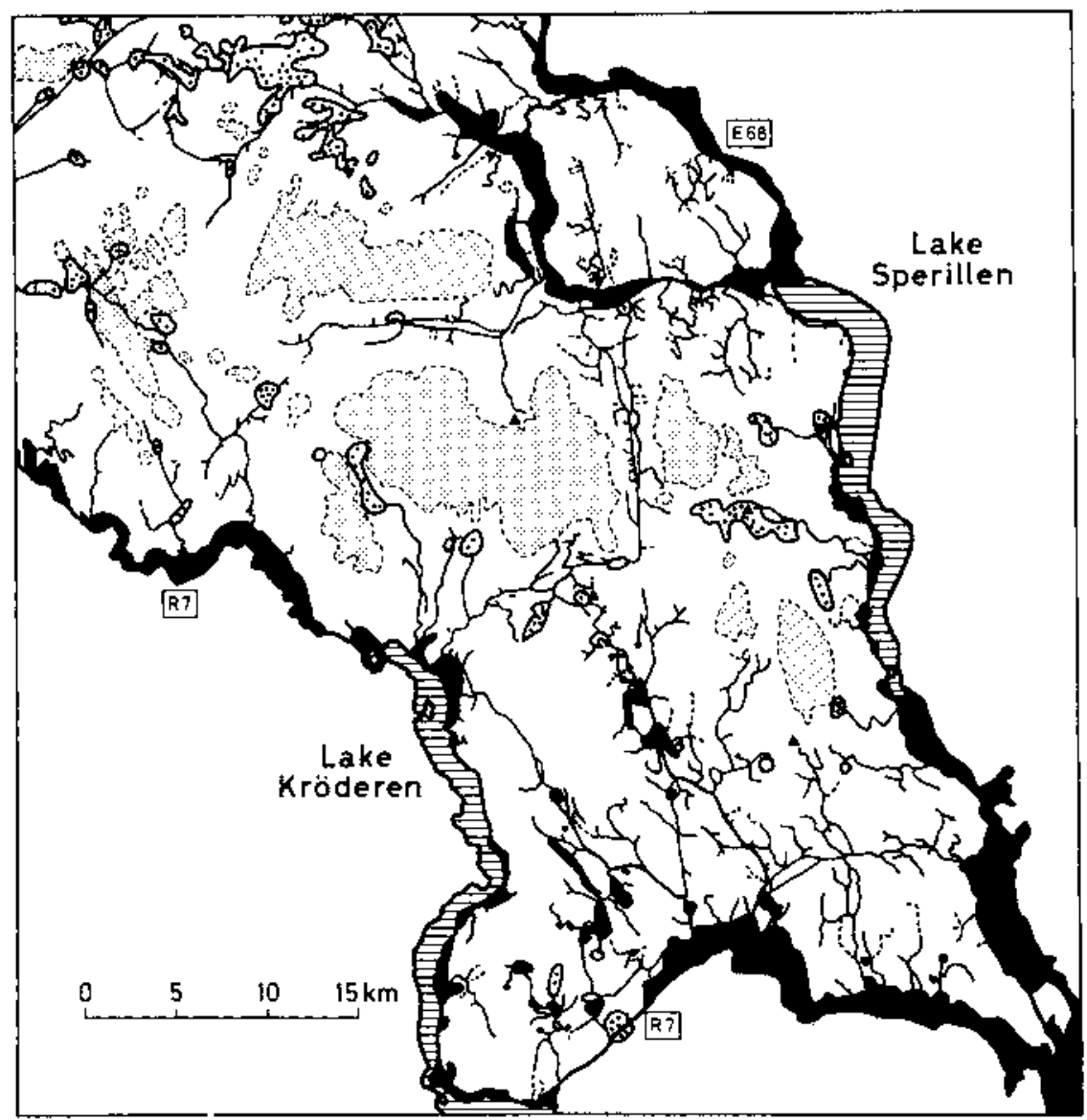

Fig. 5 (right). indicators of human activities.

Black areas: permanent habitation with agriculture, variably interspaced with forest.

Circumscribed areas with or without dots: not permanently inhabited but with 5 or more cabins or houses less than $500 \mathrm{~m}$ apart. Each dot represents 10 cabins or houses. Absence of dots indicates 5-9 cabins or houses

Triangles: lodging open to the public

$\Delta$ Apex up: Norwegian Tourist Association cabins

₹ Apex down: Mountain hostel

Thicker lines: public roads open throughout the year

Thinner lines: forestry roads, varying in quality but passable for cars, though many are closed in winter and some are open to special permit holders only.

Broken lines: tractor roads not usable by cars.

Stippled areas: above the timberline. 


\section{DISTRIBUTION}

During the period of study the bear population occurred chiefly within the boundaries of the rather restricted Main Area. The bears apparently have kept to traditional home ranges for a long time. During the study period, however, changes in distribution occurred within the area correlated with changes in the environment.

The distribution of accepted bear reports in the Main Area for the periods 1949-53 and 1969-73 is shown in Figs. 4 and 5 respectively. By comparing the two maps, a shift to a concentration in the north-western parts and a withdrawal from the southern and eastern parts are clearly visible. This change can be specified for 3 zones as follows:

\begin{tabular}{lcccc} 
& \multicolumn{2}{c}{$1949-53$} & \multicolumn{2}{c}{$1969-73$} \\
& $\mathrm{n}$ & per cent & $\mathrm{n}$ & per cent \\
\hline Zone A & 19 & 50 & 29 & 88 \\
Zone B & 12 & 32 & 3 & 9 \\
Zone C & 7 & 18 & 1 & 3 \\
\hline Sum & 38 & 100 & 33 & 100 \\
\hline
\end{tabular}

There is a clear relative increase in Zone $\mathrm{A}$ and a corresponding decrease in Zones B and C, the eastern and south-eastern areas. (Only one report is available from Zones $\mathrm{D}$ and $\mathrm{E}$ during these periods.)

There are no indications of a greater hunting pressure that might have chased the bears out of the southern and eastern areas. The most conspicuous difference is the general increase in forestry activity and, for the last 10 years, also in tourism. Both these factors are especially prevalent in these zones, as can be seen from the maps in Figs. 4 and 5 (right). In Zone B forestry is very marked to the north and cabin concentrations to the south. In the south-eastern zone forestry is specially prevalent, visualized by a relatively dense network of forestry roads.

There is thus a close correlation between human activities and changed occurrence of the bears, indicating a negative influence.

\section{POPULATION DEVELOPMENT}

The least biased parameter reflecting variations in the population are newspaper reports derived from 7 local newspapers. In the first 20 years of the study, the chances of obtaining reports from newspapers should be fairly evenly distributed.

The variation in the number of newspaper reports in the Main and Surrounding Areas is given in Fig. 6 A. The most significant result is the marked decrease in the total number of reports. In the Main Area the decrease starts in the second half of the 1950s. In the Surrounding Area the number of reports is fairly constant up to the middle of the 1960 s where there is an increase and in 
5 years reports from the Surrounding Area exceed those from the Main Area. At the end of the study period, however, there is a marked decrease in the Surrounding Area. The increase in the Main Area in the last 5-year period may or may not be real as the mechanism behind this increase is not yet understood. The chances of getting reports may have been greater due to an increased human traffic (Fig. $6 \mathrm{C}$ ), the IBP activity and a greater public engagement in conservation problems.

The most reasonable interpretation of the data is that since the end of the 1950 s there has been a gradual decrease in the total population, brought about mainly by emigration from the Main Area to more peripheral areas.

A relatively large number of females with young are reported both personally and in newspapers from the Main Area. From the Surrounding Area only 8 reports of females with young are available. Up to now 61 reports of young (14 per cent) have been received. After excluding as doubtful about 34 per cent, one is still left with 40 reports of young, of which 18 are sight records, some giving many details. A certain reproduction must ther efore have taken place.

The variation in the percentage of young in the population in the Main and Surrounding Areas is shown in Fig. $6 \mathrm{~B}$. Mean value is about 16 per cent. If only the accepted reports in the Main Area are considered, the percentage of young is only 2-4 per cent in the last 5-year period.

The litter size is reported as either one or two in both the Main and Sur rounding Areas. The mean value for both areas together is 1.3.

Most reproduction parameters are of a size order that could be expected to occur in a very small and decreasing population in which reproduction is about to come to a halt. The last visual observations of a female with young regarded as authentic are from 1969 in the Main Area and from 1972 in the Surrounding Area.

The known mortality in the study period is very small. Up to 1971 , when the bear in this area was fully protected, there was an open hunting season from 15 May to 30 October. In the eastern part of the Main Area a private protection was introduced in 1933. In the study period only one bear was shot legally in the Main Area (1956). In addition, one bear was shot in 1949 just outside the north-western border of the Surrounding Area. There is every reason to believe that no more bears were shot, because 5 municipalities had a relatively high bounty on the bear which has not been claimed.

What remains is the problem of poaching, which in the isolated Alp population in Northern Italy is regarded as an important mortality factor (Roth 1973). Enquiries made about possible illegal killing of bears have on the whole proved negative.

\section{POPULATION SIZE}

Based on the number of reports of young, a method of calculating the population number will be attempted. The calculation is based on the assumption that the relation between the number of young and the total number of bears in the population is reflected in the relation between the reports of the same two categories. One also has to assume that the chance of observing a female with young is about the same as for single bears. 


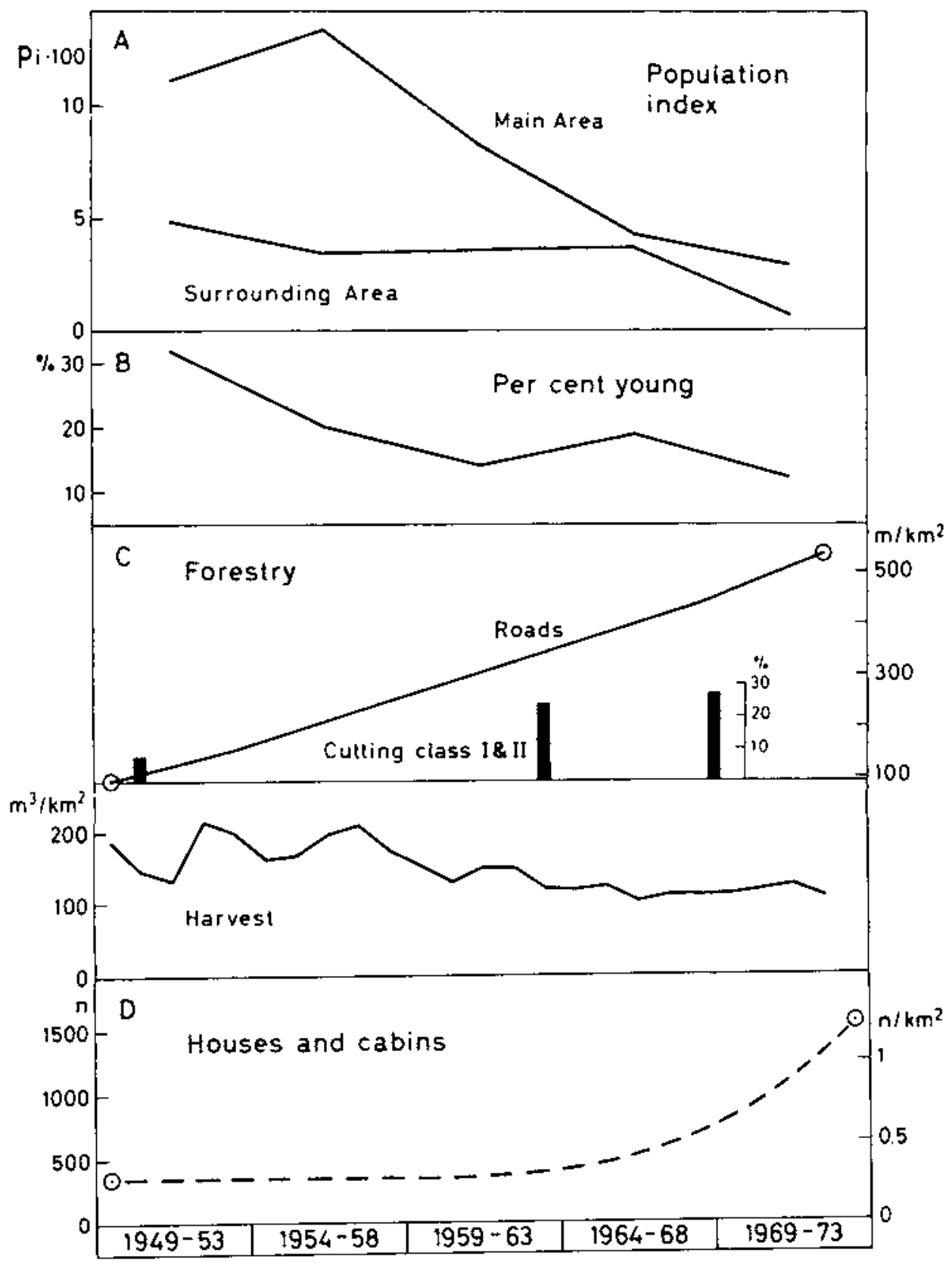


Fig. 6. Population dynamics and some parameters of forestry and tourism.

A. Number of newspaper reports per 5-year period, Main Area and Surrounding Area.

B. Per cent of young in the population in the Main and Surrounding Areas together, based on the total number of reports.

C. Roads: Mean length of forestry roads and summer tractor roads. Gradient of the curve mainly from data for the municipalities Nes, Fla and $\mathbf{S} \phi$ r-Audal. End values of the curve refer to the Main Area, derived from official and unpublished maps.

Black Bars: Percentage of cutting classes I and II; mean for the counties Buskerud and Oppland.

Harvest: Yearly lumbering harvest represented by the mean for the same three municipalities mentioned above.

(Data from Central Bureau of Statistics, Geographical Survey of Norway, and the National Forest Survey of Norway).

D. Tourism: Estimated variation in the number of houses and cabins in the Main Area, exclusive of areas with permanent habitation. End points of the curve from official maps.

On these assumptions the following equation can be set up for the 25-year period:

$$
\frac{25 \mathrm{n}}{\mathrm{y}}=\frac{\mathrm{S}_{\mathrm{r}}}{\mathrm{y}_{\mathrm{r}}}
$$

$\mathrm{n}$ : population number

$\mathrm{S}_{\mathrm{r}}$ : total number of reported bears

$y$ : number of young claimed observed under the supposition of either 1 or 2 young per year

$\mathrm{y}_{\mathrm{r}}$ : reported number of young

This equation gives for the 25-year period a mean number of about 7 in the Main Area and about 4 in the Surrounding Area. From these means maximal and minimal numbers can be calculated by use of the variations in the reports. These calculations give for the Main Area a maximum number of about 9 in the beginning of the study period and a minimum of about 5 at the end. As more than one litter is possible in some years with many reports of young, the figures given should be regarded as minimum estimates.

If the Main and Surrounding Areas are added together, the maximum and minimum values will be about 14 and 8 respectively, with the minimum in the last 5 -year period. The present number of individuals in the total population may thus be estimated to be somewhere around 5 to 8 individuals. These calculations are, of course, only approximate, but the results correspond reasonably well with previous estimates (Elgmork 1954,1966b) and the results of other censuses (Elgmork in press, IBP-CT in prep.). 


\section{BEAR-MAN RELATIONS}

The usual way of explaining relatively rapid decreases in populations of the large carnivores is excessive hunting. The bare figures for bears shot in the area and adjacent districts in the last 50 years are about 14 in the period 1923-35, about 7 in the period 1936-48, and only two in the last 25 years (Myrberget 1969, Central Bureau of Statistics, newspaper clippings, and pers. comm.). This hunting sequence may cursorily be interpreted as a reduction of a population to a critical level.

A possible reduced reproductive potential caused by too low numbers, a skewed sex distribution etc., is not, however, supported by the relatively large number of reports of young with their systematic trends. Studies of the Alp population also show that small brown bear populations with numbers down to 8-10 individuals are capable of reproducing (Roth 1970, 1973, Daldoss 1973).

The most reasonable explanation for the relatively rapid decline starting in the second half of the $1950 \mathrm{~s}$ is therefore not hunting and insufficient reproduction, but the deterioration of the habitat caused by increasing human activity.

This explanation is favoured by the changes in distribution mentioned above, showing that areas most severely influenced by man were abandoned by the bears. Also population fluctuations further back in time support this theory (Elgmork in prep.). About 1930 the bear population in this area was isolated and very small. After a private ban on hunting, mainly in the eastern areas, the population regained its number very quickly, however, and even after the shooting of about 7 bears the population at the beginning of the study period was considerably larger than in the $1930 \mathrm{~s}$. But after about 10 years it started to decrease, despite a lower hunting pressure than in the 1930s. The difference in population dynamics about 25 years apart is explained by the alterations which had taken place in the meantime in the habitat.

The first human factor which severely influenced the habitat in the study period was mechanized forestry. Throughout the period there is a clear negative correlation between length of forestry roads and number of bear reports in the different zones of the study area, with a correlation coefficient of about -0.8 (Elgmork in press). This close relation indicates a negative influence from activities connected with forestry roads, which are taken as an index of human disturbance and influence on the habitat. It is interesting to note that the decrease in bear reports had already started when the impact of all the private cabins set in.

A similar influence on a bear population caused by extensive forestry is indicated from Swedish forests (Burmann 1974). Pulliainen (1972) also regards roads and forestry activities as negative factors for the bear in Finland. In the Abruzzo population in Italy, Zunino \& Herrero (1972) indicate that logged areas may be abandoned as denning areas for many years.

The small remnant brown bear population in the Italian Alps of about 8-10 individuals, and with comparable areas, seems to be stabilized and is reproducing (Roth 1970, 1973, 1974, Daldoss 1973). As far as could be ascertained during a visit to Trentino in the summer 1974, the bear habitat in the Alps is considerably less influenced by human activities than its Norwegian counterpart. The lumbering practice is nearly exclusively a lenient selective cutting. In spite of a considerable assumed hunting pressure, the Alp bear habitat thus seems capable of sustaining a very small reproductive population.

The influence of forestry is complex, representing both an immediate direct disturbance and short and long term alterations of the habitat caused by the 
large clear-cuttings. In the early phases these lead to a reduction of the forested area and of shelter possibilities. Of importance may be the reduction of old spruce stands, which are shown to be preferred habitats in the Leningrad area by Novikov et al. (1969). A serious effect of the forestry roads is the subsequent use of the habitat for other activities.

The hiking tourists may roam over most of the area, but the great majority are presumed to follow trails. The most serious aspect of tourism in the bear area is the presence of all the private cabins. The traffic from these must represent a significant disturbance for the bears during certain times of the year.

The direct reaction of the bears to the various types of disturbance and environmental change is difficult to evaluate in detail. The bear is capable of adjusting to a certain degree of disturbance in its area, and may also occasionally accept the presence of people in the neighbourhood. Bears have e.g. been reported several times from forestry roads and clear-cut areas. On the other hand, there are reports of bears chased out by the starting of motor saws, being scared by motor vehicles, and startled by cabin owners close to the cabins. Excrement trails are occasionally reported from such incidents, indicating nervous excitement.

One aspect of such disturbances is that the animals always have to be on the alert. Radio tracking in the USA has shown that the brown bear follows the movements of the human intruder (Craighead \& Craighead 1965). However, if the human traffic becomes too complicated to follow, the bear may abandon the area. The gradual reduction in the eastern and southern parts of the Main Area, as well as the increase in the Surrounding Area in the middle of the 1960 s may be interpreted along these lines.

All the new roads, clear-cuttings and cabin concentrations may also cut off traditional migration routes and break up traditional behaviour patterns. The disturbance may also interfere negatively with food uptake and reproduction.

The shyness and the reactions to human disturbance probably change in the course of the year. The most critical period is late autumn when the bear prepares for denning. At this time, the bear is extremely shy and tries to withdraw to undisturbed areas. This may be regarded as an adaptation to a long period of co-existence with Homo sapiens L. (Craighead \& Craighead 1972). The increasing infiltration by humans and alteration of the habitat also in the denning areas is one of the most serious aspects of the impact of man in the study area.

\section{CONSERVATION MEASURES}

The first attempt to conserve the bears in this area was apparently the private initiative to reduce hunting in 1933. Of importance has been the fact that the landowners have been very restrictive in selling and leasing sites for cabins in the Vassfaret Valley. In 1973, the Vassfaret Valley and surroundings were protected against impoundment of the lakes for hydro-electrical power. In 1971, a general ban on bear hunting was introduced; and in May 1974, the building of private cabins was generally prohibited in an area of about $300 \mathrm{~km}^{2}$ in Zone A. These are, so far, the more important steps taken to preserve the bear population and its habitat.

However, much work and energy has been put into planning and discussions. 
Zoologists at the University of Oslo have been engaged in this effort by working out a conservation plan based on the present study (Elgmork 1966a \& b).

The greatest concern at present is the extension of the net of forestry roads leading to lumbering and clear-cutting in the highly elevated forests close to the known denning areas, and to an increased secondary traffic generally in the few remaining relatively undisturbed areas.

The overall problem is whether the manipulation of the ecosystem has led to such radical changes in the bear habitat that the bears are no longer capable of surviving. The limit may or may not have been reached. Very little is known of the viability of such small populations, and only further studies may give the answer.

\section{SUMMARY}

Except for one small isolated population the brown bears in Norway, Ursus arctos arctos L., consisting of probably less than 25-50 individuals, are connected with populations in neighbouring countries. The isolated population is situated in a restricted area less than $100 \mathrm{~km}$ to the north-west of Oslo in a rugged forest-alpine area which has been under increasing pressure from human activities, mainly forestry and tourism.

The population and its habitat have been under observation since 1949. There is a clear tendency towards a gradual decrease in numbers and a shift in distribution. Reproduction has taken place, but was evidently reduced to a very low frequency, if any, in the 1970s.

Direct depletion by hunting has been insignificant. The deterioration of the habitat caused by human activities is most likely the main reason for the reduction.

A plan for the conservation of this bear population was proposed in 1966, but so far few steps have been taken to preserve the bear and its habitat.

\section{REFERENCES}

BURMAN, E. 1974. Myskoxar och björnar i Härjedalen.-Sver. Nat. 65: 108110.

CRAIGHEAD, F.C.\& CRAIGHEAD, J. J. 1965. Tracking grizzly bears.-Bioscience 15: 88-92.

CRAIGHEAD, F.C.\& CRAIGHEAD, J. J. 1972. Grizzly bear prehibernation and denning activities as determined by radiotracking.-Wildl.Monogr. 32: 5-35.

DALDOSS, G. 1973. Rilievi sulla presenza dell'orso bruno nel Trentino nel quinquennio 1967-1971.-World Wildlife Fund, Club Alpino Italiano. 25 pp.

ELGMORK, K. 1954. Bjфrnen i Vassfartraktene 1949-53.-Naturen 78: 258272.

ELGMORK, K. 1962. Bjørnen i Vassfartraktene 1954-58.-Naturen 86: 36-54.

ELGMORK, K. 1966a. Plan for bevaring av bjørnestammen i Vassfartraktene. -Norsk Natur 2: 34-39. 
ELGMORK, K. 1966b. Fredningsproblemer vedrorende den siste faste bjørnestamme i $\$ \emptyset \mathrm{r}-$ Norge (Vassfarbjørnen).-Viltforskn. radets nord. konf. Sth. 1966: 99-108.

ELGMORK, K. 1969. Über den Braunbären in Norwegen.-Mitt. ÖA/W, Suppl. Der Anblick 1969: 17-20.

ELGMORK, K. in press. Norw. J. Zool.

HELLAND, A. 1913. Rovdyrene i Norge.-Tidsskr. Skogbr. 21: 334-361.

MYRBERGET, S. 1969. Den nor ske bestand av bjørn, Ursus arctos L. English summary: The Norwegian population of Brown Bear, (Ursus arctos L.).Normegian State Game Res. Inst. (2) 29: 3-21.

NOVIKOV, G. A., AYRAPETYANTS, A.E., PUKINSKY, Yu. B., TIMOFEEVA, E.K. \& FOKIN, I.M. 1969. The Brown Bear in the Leningrad oblast.-Bjull. Moskv. O-va.Isp. Pr. (In Russian).

PULLIAINEN, E. 1972. Distribution and population structure of the bear (Ursus arctos L.) in Finland.-Ann. Zool. Fennici 9: 199-207.

ROTH, H. U. 1970. Braunbären in Europa.-Natur Mensch 12: 219-224.

ROTH, H. U. 1973. Last bears in the Alps on the verge of extinction.-lUCN Bull. 4: 44 (New Ser.).

ROTH, H. U. 1974. Wiedereinbürgerung von Braunbären in Mitteleuropa.Die Pirsch 26: 391-394.

ZUNINO, F.\& HERRERO, S. 1972. The status of the Brown Bear (Ursus arctos) in Abruzzo National Park, Italy, 1971.-Biol. Conservation 4: 263-272. 